\title{
Küresel Yetkinlik Ölçeğinin Türkçe Uyarlama Çalışması ${ }^{1}$
}

\author{
DOI: $10.26466 /$ opus. 861584
}

\author{
* \\ Cansu Karaca Akarsu * - Murat Özdemir ** \\ * Okul Müdürü, Bahçeşehir Koleji, Ankara/Türkiye \\ E-Posta: sukaraca@yahoo.com \\ ORCID: 0000-0001-5700-7877 \\ ** Prof. Dr., Hacettepe Üniversitesi, Ankara/Türkiye \\ E-Posta: mrtozdem@hacettepe.edu.tr \\ ORCID: 0000-0002-1166-6831
}

Öz

Bu araştırmada Brantley-Todd (2017) tarafindan geliştirilen 'Küresel Yetkinlik Ölçĕ̆gi-KYÖ'nn Türk kültürüne uyarlanması ve öğretmen verisine dayalı olarak ölçeğin geçerlik ve güvenirliğini test etmek amaçlanmıştır. Araştırmada tarama deseni kullanılmıştır. Bu doğrultuda, betimsel yöntem uygulanmış ve nicel araştırma tekniklerinden yararlanılmıştır. Araştırma verileri 2019-2020 eğitimöğretim yılının ikinci döneminde Ankara ili merkez ilçelerinde çalışmakta olan öğretmenlerden elde edilmiştir. Bu araştırma iki farklı çalışma grubu ile iki aşamada gerçekleştirilmiştir. İlk aşama olan pilot çalışma Ankara ilinde kamu ve özel ortä̈ğretim kurumlarında görev yapmakta olan toplam 200 öğretmenle yürütülmüştür. İkinci aşama olan ana uygulamada ise Ankara ili dokuz merkez ilçesindeki kamu ortaöğretim kurumlarında görev yapmakta olan 406 öğretmenle, çalışma yürütülmüştür. KYÖ'ye ait veri setleri çeşitli varsayımlar açısından analize uygunluğu incelendikten sonra geçerlik ve güvenirlik çalışmaları gerçekleştirilmiştir. Çalışmanın pilot aşamasında ölçeğin geçerliği açımlayıcı faktör analizi (AFA) ile test edilmiştir. AFA analizi sonucunda ölçeğin, iletişim becerileri, açık fikirlilik, kendilik bilgisi ve problem çözme stilleri olarak isimlendirilen 4 faktörlü yapısı doğrulanmıştır. Ardından ana uygulamada KYÖ'nün yapı geçerliği için doğrulayıı faktör analizi (DFA) uygulanmıştır. KYÖ'nün güvenirliği ise Cronbach's Alfa katsayısı hesaplanarak değerlendirilmiştir. Analizler sonucunda kuramsal temellerle uyum gösterdiği tespit edilen 32 maddelik KYÖ'nün öğretmen görüşleri doğrultusunda geçerli ve güvenilir bir ölçme aracı olduğu sonucuna ulaşılmıştır.

Anahtar Kelimeler: Küresel Eğitim, Küresel Yetkinlik, Küresel Yeterlilik, Küresel Farkındalı, Ölçek Uyarlama.

\footnotetext{
${ }^{1}$ Bu çalışma birinci yazarın ikinci yazar danışmanlığındaki "Okul Müdürünün Inovasyon Yeterlikleri ile Öğretmenlerin Küresel Yetkinlikleri Arasındaki Ilişki" adlı doktora tezinden üretilmiştir.
} 


\title{
Turkish Adaptation Study of the Global Competence Scale $^{2}$
}

\begin{abstract}
This study aims to adapt the Global Competence Scale developed by Brantley-Todd (2017) to Turkish culture and to test the validity and reliability of the scale based on teacher data. Survey design was used in the research. In this direction, descriptive method was applied and quantitative research techniques were used. Research data were obtained from teachers working in the central districts of Anka$\mathrm{ra}$ in the second term of the 2019-2020 academic year. The study was carried out in two stages with two different study groups. The pilot study, which is the first phase, was carried out with a total of 200 teachers working in public and private secondary education institutions in Ankara. In the second phase which is the main implementation, the study was carried out with 406 teachers working in public secondary education institutions in nine central districts of Ankara. Validity and reliability studies were carried out after the data sets belonging to the Scale were examined for their suitability to analysis in terms of various assumptions. In the pilot phase of the study, the validity of the Scale was tested by exploratory factor analysis (EFA). As a result of EFA analysis, the 4-factor structure of the scale named as communication skills, open-mindedness, self-knowledge and problem solving styles was confirmed. Then, in the main application, the construct validity of the Scale was tested by confirmatory factor analysis (CFA). The reliability of Scale was evaluated by calculating Cronbach's Alpha coefficient. As a result of the analysis, it was concluded that the 32-item Global Competence Scale, which was determined to comply with the theoretical foundations, was a valid and reliable measurement tool in line with the teachers' opinions.
\end{abstract}

Keywords: Global Education, Global Competence, Global Competency, Global Awareness, Scale Adaptation.

\footnotetext{
${ }^{2}$ This study was derived from the doctoral dissertation of the first author, under the supervision of the second author, entitled "The Relationship Between The School Principal's Innovation Qualifications And Teachers 'Global Competences".
} 


\section{Giriş}

Dünyanın küçülmesi ile birlikte imkanlar ve imkansızlıklar, zenginlik ve fakirlik, adalet ve adaletsizlik, özgürlük ve baskı, eşitlik ve eşitsizlik, hoşgörü ve tahammülsüzlük gibi birbirine zit unsurların gündelik yaşamda daha fazla bir arada olduğu bir çağ başlamıştır. Holton (2000) bu çağ küresel çağ olarak adlandırmaktadır. Küreselleşmeyle birlikte ülkeler arasındaki gelişmişlik düzeyi de giderek derinleşmektedir. Bu sebeple bir yandan eşitsizliklerle mücadele etmek bir yandan da küresel bir bilinç oluşturmak Birleşmiş Milletler (BM) olmak üzere çeşitli çok uluslu örgütün ana gündem maddelerinden biri halinde gelmiştir. Bu kapsamda 2015 yılında Birleşmiş Milletlere üye 193 ülke yoksulluğa son vermeyi, eşitsizliklerle mücadele etmeyi ve çevrenin korunmasını amaçlayan Sürdürülebilir Kalkınma Amaçlarını oy birliği ile kabul etmiştir. Daha adil, insanlığın ortak yararı için uğraşan, daha kapsayıcı bir dünya yaratmada en güçlü aracın eğitim olduğu fikriyle; herkes için nitelikli eğitime odaklanan 4 . Amaç bilinçli bir şekilde okuma becerileri, matematik, fen bilimleri gibi temel bilgi ve becerilerin yanı sıra sürdürülebilir bir ortak yaşamın öğrenilmesinin önemini de vurgulamıştır (Schleicher, 2017). Bu doğrultuda Uluslararası Öğrenci Değerlendirme Programı (PISA), Küresel yetkinliği ilk olarak 2018 yllındaki sınavda ölçmek üzere değerlendirme kapsamına almıştır (OECD, 2018). PISA'nın küresel yetkinlik değerlendirmesi, eğitim aracılığıyla, ülkelere daha sürdürülebilir toplumlar yaratabilmek için ihtiyaç duydukları verileri sağlamaktadır. Eğitim sistemlerinin, gençlerin birbirlerinin ve yakın çevrelerinin ötesindeki dünyayı anlamaya ve uyumlu topluluklar oluşturarak eyleme geçmeyi teşvik eden öğrenim ortamları oluşturacak şekilde düzenlenmelerine dair çabalara kapsamlı bir bakış açısı getirmeye çalışmaktadır (OECD, 2018a).

Küresel yetkinlik (Global competence) terimi, uluslararası araştırmalar ve küresel eğitim ile ilgili olarak 20. yüzyılda sunulan fikirlerle pek çok bağlantıya sahipken, 2011'den önce neredeyse hiç kullanılmamıştır. Asya Topluluğu, "küresel yetkinlik" terimini, kendi Uluslararası Okulları Ağı için kullanmıştır (Boix-Mansilla ve Jackson, 2011). Boix-Mansilla ve Jackson (2011) bu kavramı tanıtmakta, detaylandırmakta ve küresel yetkinlik stratejilerinin lise müfredatına entegre edilmesinin gerekçesini sunmaktadır.

Küresel ve kültürlerarası bir bakış açısı geliştirmek, eğitimin hem dünya hem de kendi yaşamları için önemli ölçüde şekillendirilebildiği yaşam boyu 
bir süreçtir. Okullarda öğrencilere çeşitli sosyal medya platformlarını ve bu platformlardan edinecekleri bilgiyi nasıl daha yetkin ve sorumluluk sahibi bireyler olarak kullanabileceklerinin öğretilmesinin önemini bunun yanı sıra öğrencilerin farklı halklar, diller ve kültürler için bir takdiri teşvik eden deneyimlere katılmalarına izin vererek kültürlerarası duyarlılığı ve saygiyı teşvik edecek ortamlar düzenlemelerinin öneminin kimi yazarlarca altı çizilmektedir (Bennett, 2004; Sinicrope, Norris ve Watanabe, 2007). Bu konudaki öncü araştırmacilardan Boix-Mansilla ve Jackson (2011) okulların gençlerin toplumdaki ve dünyadaki yerlerini anlama yeteneklerini geliştirmek ve kendi fikirlerini oluşturmak ve harekete geçme yeteneklerini geliştirmek için benzersiz bir konuma sahip olmalarının önemini vurgulamaktadır.

Yirmi birinci yüzyllda yetişen gençler için küresel yetkinliğin niçin başl1ca bir yetkinlik olması gerektiği hususunda üç temel gerekçeden söz edilmektedir. Bu gerekçeler Boix-Mansilla ve Jackson'ın (2011) çalışmalarında; küresel ekonomi ve değişen iş talepleri, eşi görülmemiş çapta küresel göç, son olarak da iklim dengesizliği ve çevresel yönetim olarak sıralanmaktadır. Küresel yetkinliğin bir diğer gerekçesi de aynı zamanda dünyayı incelemenin değerine ve öğrencilerin öğrenmeye derinlemesine katılımına katkı sağlamaktır. Dünyadaki farklı kültürler, uluslararası sistemler ve küresel konular gibi günümüz dünyasının konuları öğrencilerin dikkatini çekerek öğrenmeye katkılarını artıracaktır (Mansilla ve Gardner, 2007).

Küresel yetkinliğin kavramsallaştırılması ve kuramsal temellerinin atılması konusunda Hanvey'in (1976) makalesi önemli bir rol oynamıştır. Hanvey (1976) bu makalesinde eğitimin bakış açısının gezegenin durumu ve kültürlerarası farkındalık, küresel dinamikler bilgisi ve insanın seçimlerinin farkındalığını içeren düşünce biçimleri geliştirmeye yönelik olması gerektiğini ifade etmektedir. Hanvey'in (1976) tanımında eğitim uluslar, kültürler ve medeniyetlerin incelenmesine odaklanmalıdır. Bu noktada Hanvey özellikle Amerika Birleşik Devletleri'nin çoğulcu toplumunu diğer halkların toplumlarıyla ilişkisini, birbirleriyle nasıl bağlantılı olduklarını, birlikte nasıl değiştiklerini ve bu süreçteki bireyin rolünü anlamaya odaklanan bir eğitim bakış açısı tarif etmektedir (Villereal, 2009). Ulaşılan kaynaklarda ilk olarak Kniep (1989), öğrencileri küreselleşmiş ve birbirine bağlı bir dünya için daha iyi bir şekilde hazırlama ihtiyacını belirlemiş ve öğrencileri bu gerçekliğe hazırlamak için bir sosyal bilgiler müfredatı oluşturmaya çalışmıştır (akt. Gaudelli ve Fernekes, 2004). Kniep, "kişinin tarihsel bir bakış açısı sağlamak, 
model ve sistemleri algılamasına yardımcı olmak ve sosyal katılım için temel sağlamak" olarak özetlediği küresel sosyal bilgiler müfredatı için beş kavramsal tema öngörmüştür (Gaudelli ve Fernekes, 2004). Bunlar: dayanışma, değişim, kültür, kıtlık ve çatışma olarak sıralanabilmektedir. Kniep'e göre bu beş tema, öğrencilerin küresel bir bakış açısı ve çok kültürlü bir farkındalık geliştirmelerine yardımcı olmaktadır. Dahası, Kniep, sosyal bilgiler alanında dört küresel sorun kategorisi oluşturmuştur: Öğrencilerin çözüm geliştirmeyi öğrendikleri bu alanlar: sulh ve güvenlik, ulusal, uluslararası gelişim, çevre problemleri ve insan haklarıdır (Gaudelli ve Fernekes, 2004). Günümüzde de çoğu küresel sorun, bu dört kategoriden birinde incelenebilmektedir.

Reimers (2009), küresel yetkinliğin doğası üzerine şu görüşe sahiptir: Küresel yetkinlik, İnsanların yaşadıkları düz dünyayı anlamalarına yardımCı olan bilgi ve becerilerdir. Bunun yan sıra küresel meseleleri ve olayları kavramayı ve bunlara hitap etmek için olanaklar yaratmayı sağlayacak disiplinler arası alanlara entegre olma becerileridir. "Düz dünya" ifadesi Friedman'in (2005) okuyucunun dikkatini çekmek için bir metafor olarak kullandığı bir ifadedir. Friedman (2005) düz dünya metaforuyla internetin keşfi, kıtalararası fiber-optik kabloların döşenmesi vb. sebeplerle iletişimin hızlanması ile birlikte gelişmekte olan ülkelerin bireylerinin eşit şartlarda gelişmiş ülkelerdeki bireylerle rekabet edebileceğini iddia etmektedir. Yazar, internetin keşfi ve iletişim hızının artmasıyla birlikte küreselleşmenin yeni bir çağa girdiğini, bu durumun yıllar içinde dünyayı düzleştirdiğini ve bunu yapmaya devam edeceğini iddia etmektedir (Friedman, 2005). BoixMansilla ve Gardner ise "kendimizi ve temas ettiğimiz insanları, nesneleri ve durumları, çağdaş dünyamızın daha geniş matriksine yerleştirme kapasitesini ve eğilimini" vurgulayan "küresel bilinç" üzerine bir bakış açısı sunmuşlardır (Mansilla ve Gardner, 2007). Uluslararası Bakalorya Organizasyonu (IBO), hedeflerinden birini "uluslararası fikirlilik" geliştirmek, bu tanımın, dünyayı öğrenme için en geniş bağlam olarak değerlendiren, bir dizi konuda kavramsal anlayış geliştiren ve araştırma yapma, yansıtma, harekete geçme firsatları sunan bir eğitim görüşü içerdiğini belirtmektedir (IBO, 2012).

Amerika Birleşik Devletleri'nde, öğrencileri küresel sahnede iş birliği yapmaya ve yarışmaya hazırlamanın önemini vurgulayan farklı çalışmalar da mevcuttur (Kagan ve Stewart 2004a, Kagan ve Stewart 2004b, Stewart, 
2005, Wagner, 2008, Hersi, 2010, Darling-Hammond, 2010). Son y1llarda dünyadaki diğer ülkelerde de okul müfredatlarında öğrencilere daha fazla uluslararası anlayış aşılamaya yönelik girişimlerin ortaya çıtığı görülmektedir. Örneğin, Maastrich Küresel Eğitim Bildirgesi'nde yer alan belgede, Avrupa Konseyi temsilcileri, "insanların gözlerini ve zihinlerini dünyanın gerçeklerine açmak ve herkes için insan hakları, eşitliğin sağlanması gibi onları daha adaletli bir dünya yaratmak için uyandırmak üzere tasarlanmış küresel eğitim" için bir çerçeve sunmuştur. Bu liderlerin görüşüne göre, küresel eğitimin insan hakları, sürdürülebilirlik, barış ve çatışmanın önlenmesi, kültürlerarasılık ve vatandaşlık eğitimini kapsadığı, ancak bunlarla sınırlı olmadığ1 düşünülmektedir (O'Loughlin ve Wegimont, 2002). Büyük Britanya'da, Uluslararası Kalkınma Departmanı, Birleşik Krallık okullarını Afrika, Asya, Latin Amerika ve Karayipler'deki okullara bağlayan Küresel Ortaklık Okulları programı aracılığıyla küresel kalkınma konularını resmi müfredata entegre etmeye çalışmıştır (Global partnership, 2019). İsveç'te, Küresel Vatandaş Programı öğrencileri, öğretmenleri ve okul liderlerini İsveç'in geleceği için önemli öneme sahip ülkeleri anlamaya hazırlamaktadır; Çin ve Hindistan'daki okullarla yapılan ortaklıkların, öğrencileri yurtdışından eğitimden sürdürülebilir kalkınmaya, kurumsal sosyal sorumluluk, ekonomi ve finansla uğraşmaya kadar dünyanın gerçek taleplerine hazırladığı düşünülmektedir. Hindistan'da, uluslararası eğitime yönelik çabalar eski şiddet karşıtı ve evrensel kardeşlik gelenekleri üzerine kuruludur. Hindistan'ın Okul Eğitimi için Ulusal Müfredat Çerçevesi, ulusal kimliği ve birliği teşvik eden bir okul müfredatı gerektirmektedir, aynı zamanda "tüm insanlığın refahı için uluslar arasında barışı ve anlayışı teşvik etme gerekliliği bilincini artırmaya" çalışmaktadır. Çerçeve, barış ve insan hakları eğitimine yönelik özel müfredatlar önerilmiş olsa da uluslararası eğitimin mevcut konulara dahil edilmesini beklenmektedir (Boix-Mansilla ve Jackson, 2011; UNESCO, 2014 ve 2015).

2013 yılında devletler PISA'dan uluslararası değerlendirmelerinde küresel yetkinlik ile ilgili ölçütler geliştirme imkanlarının araştırılmasını talep etmişlerdir. Bu noktada küresel yetkinlik, insanların dünyayı başka bir gözle görmelerini ve farklı fikirleri, bakış açılarını, değerlerini takdir etmelerini sağlayan beceriler toplamı olarak adlandırılmaktadır (Schleicher, 2017). PISA, küresel yetkinlik kavramının bir hayat boyu öğrenme hedefi olarak ele alınması gerektiğini ve kavramın farklı boyutlardan oluştuğuna dikkat 
çeker. Küresel yetkinlik, "küresel ve kültürlerarası meseleleri eleştirel olarak ve farklı açılardan çözümleme, farklılıkların kişinin ve başkalarının algılarını, yargılarını ve düşüncelerini nasıl etkilediğini anlama ve farklı kültürlere sahip başkalarıyla insan onuruna duyulan ortak saygı temelinde açık, uygun ve etkili iletişime geçebilme kapasitesi" olarak tanımlanır (OECD, 2018). Buna göre küresel yetkin sayılan bireyler; yerel olduğu kadar küresel ve kültürler arası konuları da araştırabilen, birbirinden farklı bakış açlarına ve çok farklı dünya görüşlerine saygı duyabilen, başkalarıyla saygılı bir şekilde etkileşime geçebilen, tüm bunların yanında insanlığın ortak refahı ve sürdürülebilir yaşam için harekete geçen kişilerdir (Boix-Mansilla ve Jackson, 2012; OECD, 2018). Bu tanım, insanların günlük yaşamlarında başarılı bir şekilde sürdürmeleri gereken küresel yetkinliğin dört hedef boyutunu özetlemektedir. Küresel yetkinliğin söz konusu boyutları bilgi, değerler, tutumlar ve becerilerdir.

Bilgi: Yerel ve küresel açıdan anlamlı konuları irdelemek: Bu boyut, insanların küresel bir konu hakkında görüşlerini oluştururken dünyaya dair bilgileriyle eleştirel düşünceyi birlikte yürütme becerisini tanımlamaktadır (OECD, 2018a). Küresel açıdan yetkin olarak tanımlanan öğrenciler, okulda edinilen bilgiyi ve düşünme becerilerini; yerel, kültürel ya da küresel bir konu hakkında sorular sormak, verileri ve iddiaları çözümlemek, olguları açıklamak ve kendilerine ait bir duruş sergilemek için bir araya getirebilmelidirler (Boix-Mansilla ve Jackson, 2011). Bu öğrenciler ayrıca medyanın verdiği mesajlara erişirken, bu mesajları eleştirel olarak değerlendirip çözümleyebilmekte hatta yeni medya içerikleri üretebilir durumda olmalıdırlar (Buckingham, 2007; Kellner ve Share, 2005).

Değerler: Farklı bakış açıların ve dünya görüşlerini anlamak ve takdir etmek: Bu boyut, küresel sorunları birbirinden çok farklı bakış açılarıyla ele alma niyeti ve kapasitesini vurgular (OECD, 2018a). Bireyler, farklı kültürlerin tarihi, değer yargıları, iletişim biçimleri, inançları ve adetleri hakkında bilgi edindikçe kendi bakış açılarının ve tutumlarının pek çok etki ile oluştuğunu ve başkalarının kendilerininkinden tamamen farklı doğrulara sahip olabildiğini fark etmeye başlar (Hanvey, 1976; OECD, 2018a). Farklı bakış açıları ve dünya görüşleriyle bağ kurabilmek bireylerin başkalarının ve kendi kabullerinin ve çkarımlarının irdelenmesini gerektirmektedir. Bu- 
nunla birlikte bireyleri birbirinden farklı kılan nitelikleri tanıyan ve takdir eden kişiler gündelik hayatlarında adaletsizliği kabullenmeye daha az yatkın olurlar. Diğer yandan, bu değerleri içselleştiremeyen kişilerin "farklı" olanlara karşı önyargılı davranmaya daha yatkın olması mümkündür (Fennes and Hapgood, 1997; OECD, 2018a).

Tutumlar: Farklı kültüre sahip bireylerle açık, uygun şekilde ve etkili etkileşimlerde bulunmak: Küresel olarak yetkin bireyler davranışlarını ve iletişim tarzlarını farklı kültürlerden gelen bireylerle iletişim kurarken uygun şekilde ayarlayabilirler. Saygılı diyalog kurarak, karşısındakini anlamaya çalışır ve ötekileştirilmiş grupları da kapsamaya gayret ederler. Bu boyut, bireylerin açık, uygun ve etkili iletişim becerileri geliştirerek kültürler arası farklılıklar arasında bağ kurma kapasitesini vurgular (OECD, 2018a). "Açık" etkileşim, etkileşimde bulunan bireylerin diğerlerinin bakış açısına duyarlllik göstererek, ilgiyle yaklaşarak etkileşimde bulunma niyetini ifade eder. "Uygun şekilde" nitelemesi ise, tüm tarafların kültürel olarak normlarına gösterilen saygıya işaret eder. "Etkili” iletişimde ise, tüm katılımcılar kendilerinin doğru anlaşılmasınıa gayret eder ve diğerlerini de doğru anlayabilir (Barrett, Byram, Lazar, Mompoint-Gaillard ve Philippou, 2013).

Beceriler: Ortak esenlik ve sürdürülebilir kalkınma için harekete geçmek: $\mathrm{Bu}$ boyut, genç insanların toplumun etkin ve sorumlu üyeleri olarak aldıkları rollere odaklanır ve bireylerin yerel konular gibi küresel veya kültürler arası meselelere de çözüm üretme hazır bulunuşluklarına işaret eder. Gençlerin her durumda etkili olabileceğini savunur. Bu anlamda yetkin kişiler bilgili ve üzerinde düşünülmüş eylemlere girişmek için firsatlar yaratır ve seslerinin duyulmasını sağlar. Harekete geçmek, kimi zaman insanlık onuru tehdit edilen bir arkadaşını savunmak, kimi zaman da okulda küresel çapta dahi olabilecek bir medya kampanyasına ön ayak olmak veya sosyal medya aracılığıyla göçmen sorunlarıyla ilgili kişisel görüşünü savunmak anlamı taşıyabilir. Küresel düzeyde yetkin olan bireyler, içinde yaşadıkları toplumun yaşam koşullarının iyileşmesi için ayırdıkları enerji kadar, daha adil, barış̧̧l, daha kapsayıcı ve çevresel sorunlara da duyarlı, sürdürülebilir bir dünya kurulmasına katkıda bulunmaya çalışır (OECD, 2018a).

Küresel yetkinliğe ilişkin uluslararası yazın incelendiğinde küresel yetkinliğin özellikle son yıllarda ele alınan bir kavram olduğu belirlenmiştir. 
Küresel yetkinlik ile ilgili araştırmalar, iş dünyası (Adler ve Bartholomew, 1992; (Bismuth ve Edmundson, 1994; Miller 1994; Swiss Consulting Group 2002), mühendislik (Sangster, 1994) küresel sağlik (Wilson, 2012; Wilson vd. 2014), uluslararası çalışmalar (Jackson, 1994; Stohl, 1994), gazetecilik (Huebner, 1994) ve hukuk (Young, 1994) akt. Brantley-Todd, 2017) gibi birçok alana fayda sağlarken bir yandan da uluslararası eğitim bağlamında öncül araştırmalar yapılmıştır (American Counsil on Education's (ACE) Commission on International Education, 1998; Council on International Educational Exchange (CIEE), 1993; Hunter, White, Godbey, 2006; Lambert, 1994, akt. Brantley-Todd, 2017; Van Roekel, 2010). Eğitim bağlamında küresel yetkinlik kültürlerarası eğitim, küresel vatandaşlık eğitimi ve demokratik vatandaşlık eğitimi gibi farklı küresel eğitim modellerinin fikirlerine dayanmaktadır (UNESCO, 2014a; Council of Europe, 2016).

Küresel yetkinlik birçok bağlamda geliştirilebilir ancak bu konuda okulların payına düşen görev hayati bir görevdir. Okullar genç insanlara hem genel ölçekte dünya hem de kendi yaşamları açısından anlamlı gelişmeler eleştirel bir gözle irdeleme fırsatları sunabilir (Bennet, 2004). Öğrenciler, dijital bilgileri ve sosyal medya platformlarını eleştirel bir yaklaşımla ve sorumluluk duygusuyla nasıl kullanacaklarını okullarda öğrenebilirler (Buckingham, 2007). Öğretmenler öğrencileri farklı kültürlerle iletişim kurarak deneyimler kazanmalarını özendirerek kültürler arası duyarlılık ve saygıyı teşvik edebilir (OECD, 2018; OECD, 2018a). Ancak birçok öğretmen ve okul liderinin müfredatlarına küresel yetkinliği aşılama konusunda önceden eğitimi yoktur. Ayrıca, çoğu öğretmen öğretim programlarına küresel farkındalığı veya küresel yetkinliği dahil etmemekte ya da bunlara vurgu yapmamaktadır (Cushner ve Brennan'dan akt. Felch, 2016). Küresel eğitim, 21. Yüzyıl becerileri, öğretmen yetkinliği, özyeterlik gibi birçok kavramla yakından ilişkili olan küresel yetkinlik kavramının Türkiye bağlamında araştırılması da önemli görülmektedir. Ancak, bu konuda Türk araştırmacllar tarafından geliştirilmiş bir ölçme aracı bulunmamaktadır. Brantley-Todd (2017) bu kapsamda öğretmen görüşlerine dayalı olarak küresel yetkinliği incelemek, ölçmek ve değerlendirmek üzere bir ölçme aracı geliştirmiştir. Ulaşılan kaynaklarda ilk kez Brantley-Todd (2017), uluslararası yazında da yeni bir kavram olan küresel yetkinlik kavramın eğitim bağlamında ele alarak bir ölçme-değerlendirme aracı geliştirmiştir. Brantley-Todd'un (2017) geliştirdiği Küresel Yetkinlik Ölçeği küresel yetkinliğe yönelik bütünleşik 
yapının dört boyutunu kapsayan 48 maddeden oluşmaktadır. Bu kapsamda mevcut araştırmanın gerekçesi Küresel Yetkinlik Ölçeği'nin geçerlik ve güvenirliğinin Türk kültüründe sinanması ve böylece ölçeğin Türkçeye uyarlanmasıdır. Küresel yetkinliğin Türkiye bağlamında da uluslararası alanyazınla eşzamanlı şekilde incelenmesi ve ölçeğin Türkçeye uyarlanması küresel yetkinlik konusunda araştırma yapmak isteyen bilim insanlarına veri toplama sürecinde katkı sağlayabilir.

Bu bağlamda araştırmanın amacı, Brantley-Todd (2017) tarafından geliştirilmiş olan Küresel Yetkinlik Ölçeğinin (KYÖ) Türkçe uyarlamasını yapmak ve öğretmen verisine dayalı olarak ölçeğin geçerlik ve güvenirliğini test etmektir. Bu kapsamda çalışmada aşağıdaki sorulara yanı aranmıştır;

1. KYÖ, Türk kültüründe geçerli bir veri toplama aracı mıdır?

2. KYÖ, Türk kültüründe güvenilir bir veri toplama aracı mıdır?

\section{Yöntem}

Bu araştırmada, Brantley-Todd'un (2017) geliştirdiği Küresel Yetkinlik Ölçeği'nin Türkçeye uyarlama çalışmasının yürütülmesi, geçerlik ve güvenirliğinin sınanması amaçlanmıştır. Araştırmada tarama deseni kullanılmıştır. Bu doğrultuda, betimsel yöntem uygulanmış ve nicel araştırma tekniklerinden yararlanılmıştır.

\section{Çalışma Grubu}

Bu araştırma iki farklı çalışma grubu ile iki aşamada gerçekleştirilmiştir. İlk aşama olan pilot çalışma 2019-2020 Bahar döneminde Ankara ilinde kamu ve özel ortaöğretim kurumlarında görev yapmakta olan toplam 200 öğretmenle yürütülmüştür. Örneklem büyüklügüne ilişkin alanyazın incelendiğinde, örneğin Tabachnick ve Fidell'in (2012) faktör yapısının belirgin ve az sayıda olduğu durumlarda faktör analizi yapmak için örneklem büyüklügünün 100'e indirilebileceğini ancak güvenilir sonuçlar elde etmek için 200 deneklik bir örneklem büyüklügünü gerekli bulduğu belirlenmiştir. Örnekleme tekniği için kolay ulaşılabilir örnekleme seçilmiştir. Bu teknik hızlı, ekonomik ve ulaşılması kolay evrenlere uygunluğuyla tanımlanmaktadır (Patton, 2005). Bu sayede Covid-19 pandemisi sirasında verileri elde ederken zaman açısından önemli avantajlar sağlamıştır. 
İkinci aşamada ise örneklem seçiminde "tabakalı örnekleme" yöntemi kullanılmıştır. Bu yöntem evrendeki alt grupların bu evrendeki ağırlıkları oranında örneklemede temsil edilmelerini amaçlamaktadır. Örneklem oluşturma sürecine 2019-2020 eğitim-öğretim yılında Ankara ili dokuz merkez ilçesinde bulunan resmi ortaöğretim kurumları ve bu okullarda çalışan öğretmenlerin sayısının tespit edilmesiyle başlanmıştır. Bu kapsamda Altındağ'da 10, Çankaya'da 36, Etimesgut'ta 10, Gölbaşı'nda 4, Keçiören'de 15, Mamak'ta 16, Pursaklar'da 3, Sincan'da 7 ve Yenimahalle'de 17 resmi lisede toplamda 6101 öğretmenin görev yaptığı tespit edilmiştir. Örneklem büyüklüğünün belirlenmesi işleminde "Örneklem Büyüklükleri Tablosundan" yararlanılmıştır. Bu kapsamda araştırmanın 6101 öğretmenden oluşan hedef evreninin $\alpha=.05$ anlamlılık ve \%5 hoşgörü düzeyinde 362 öğretmenin temsil edebileceği var sayılmıştır (Balcı, 2005: 95). Öte yandan örneklem büyüklügü belirlenirken ölçek geliştirme ve ölçek uyarlama çalışmalarında geçerlik ve güvenirlik analizlerinde daha doğru sonuçların elde edilebilmesi için katılımcı sayısının madde sayısının 5 katından yüksek olması ölçüt alınmıştır (Balc1, 2005; Büyüköztürk, Kılıç Çakmak, Aygün, Karadeniz ve Demirel, 2013, s.136). Bu doğrultuda, KYÖ'nün toplamda 48 maddeden oluştuğu ve birçok psikometri uzmanı tarafından ortaya konulan örneklem büyüklüğü ölçütleri göz önünde bulundurulduğunda Ankara ili 9 merkez ilçesinde toplam 400 öğretmenden oluşan örneklem büyüklügünün geçerlik ve güvenirlik analizleri için uygun olduğuna karar verilmiştir. İki aşamalı ölçek uyarlama çalışmasına ilişkin ayrıntılar Tablo 1' de sunulmuştur.

Tablo 1'de görüldüğü üzere araştırmanın her iki aşamasında da ulaşılması gereken sayı ve oran sağlanmıştır. Araştırmanın pilot aşamasında katılımcı öğretmenlerin cinsiyetleri incelendiğinde \%72'sinin kadın; mesleki kıdem dağılımları incelendiğinde, \%49.5'inin 1-10 yıl arası kıdeme sahip olduğu saptanmıştır. Katılımcıların branşları fizik, kimya, biyoloji ve matematik, fen bilimleri; tarih, coğrafya, felsefe grubu ve edebiyat, sosyal bilimler; resim, beden, müzik, satranç, drama, bilişim disiplinleri ise uygulamalı dersler branşlarında toplanmıştır. En yüksek katılım oranı \%36.5 ile sosyal bilimler branşındandır.

Araştırmanın ana uygulama aşamasında ise katılımcı öğretmenlerin mesleki kıdem dağılımları incelendiğinde, katılımcılardan 245'inin (\%60) mesleki kıdeminin 1-10 yıl arası, cinsiyet dağılımları incelendiğinde ise \%69.2'sinin kadın olduğu saptanmıştır. Çalışmanın ana uygulama aşama- 
sında da katılımcıların branşları arasındaki en yüksek oran \% 35.4 ile sosyal bilimlerdir.

Tablo 1. KYÖ'ye ait Veri Toplama Çalışmalarının Ayruntıları

\begin{tabular}{|c|c|c|c|c|c|c|}
\hline \multirow[t]{2}{*}{ Aşama } & \multirow[t]{2}{*}{$\begin{array}{l}\text { Katılımc } \\
\text { Cinsiyetleri }\end{array}$} & \multirow[t]{2}{*}{ Sayılar (n) } & \multirow[t]{2}{*}{ Oranlar (\%) } & \multicolumn{3}{|c|}{ Katılımcıların Eğitim Düzeyleri } \\
\hline & & & & & (n) & $(\%)$ \\
\hline \multirow{3}{*}{$\begin{array}{l}\text { Aşama } 1 \\
\text { (Pilot Uygu- } \\
\text { lama) }\end{array}$} & Kadın & 144 & 72,0 & Lisans & 156 & 78,0 \\
\hline & Erkek & 56 & 28,0 & Lisans üstü & 44 & 22,0 \\
\hline & Toplam & 200 & 100,0 & Toplam & 200 & 100,0 \\
\hline \multirow{3}{*}{$\begin{array}{l}\text { Aşama } 2 \\
\text { (Ana Uygu- } \\
\text { lama) }\end{array}$} & Kadın & 281 & 69,2 & Lisans & 354 & 87.2 \\
\hline & Erkek & 125 & 30,8 & Lisans üstü & 52 & 12.8 \\
\hline & Toplam & 406 & 100,0 & Toplam & 406 & 100,0 \\
\hline \multirow[t]{2}{*}{ Aşama } & $\begin{array}{l}\text { Katılımcı } \\
\text { Kıdemleri }\end{array}$ & Sayılar (n) & Oranlar (\%) & \multicolumn{3}{|c|}{ Katılımcıların Branşları } \\
\hline & & & & & (n) & $(\%)$ \\
\hline \multirow{5}{*}{$\begin{array}{l}\text { Aşama } 1 \\
\text { (Pilot Uygu- } \\
\text { lama) }\end{array}$} & $1-10$ yıl & 99 & 49.5 & Fen Bilimleri & 57 & 28.5 \\
\hline & $11-20$ yll & 59 & 29.5 & Sosyal Bilim. & 73 & 36.5 \\
\hline & $21-30 \mathrm{yll}$ & 37 & 18.5 & Yabancı Dil & 34 & 17 \\
\hline & 31 yıl ve üst & 5 & 2.5 & $\begin{array}{l}\text { Uygulamalı } \\
\text { D. }\end{array}$ & 36 & 18 \\
\hline & Toplam & 200 & 100 & Toplam & 200 & 100 \\
\hline \multirow{5}{*}{$\begin{array}{l}\text { Aşama } 2 \\
\text { (Ana Uygu- } \\
\text { lama) }\end{array}$} & $1-10 \mathrm{yll}$ & 245 & 60.34 & Fen Bilimleri & 111 & 27.3 \\
\hline & $11-20 \mathrm{yll}$ & 96 & 23.65 & Sosyal Bilim. & 144 & 35.4 \\
\hline & $21-30 \mathrm{yll}$ & 53 & 13.05 & Yabancı Dil & 64 & 15.8 \\
\hline & 31 yıl ve üst & 12 & 2.96 & $\begin{array}{l}\text { Uygulamalı } \\
\text { D. }\end{array}$ & 87 & 21.5 \\
\hline & Toplam & 406 & 100 & Toplam & 406 & 100 \\
\hline
\end{tabular}

\section{Veri Toplama Aracı}

Araştırmada katılımcılara Brantley-Todd'un (2017) geliştirdiği Küresel Yetkinlik Ölçeği (KYÖ) uygulanmıştır. KYÖ küresel yetkinliğe yönelik bütünleşik yapının dört boyutunu kapsayan maddelerden oluşmaktadır. KYÖ öğretmenlere, eğitim yöneticilerine, denetçilerine uygulanmak üzere, küresel yetkinlik hakkında temel bilgiler oluşturmalarına yardımcı olmak amacıyla tasarlanmıştır. Brantley-Todd (2017) tarafından geliştirilen KYÖ dört bölüm ve ilk üç bölümü 48 maddelik dörtlü Likert tipinde derecelendirilmiş, dördüncü bölümü açık uçlu sorulardan oluşan bir veri toplama aracıdır. KYÖ'nün bölümleri (i) eğilim-duygusal alan, açık fikirlilik (örn: 'Diğger toplumlarda yaşayan insanların doğru ve yanlış hakkındaki farkl görüşlerinin onlar için geçerli olabileceğine inanırım') on altı madde, (ii) bilgi-kendilik bilgisi (örn: 'Gerektiğinde, geçmişteki davranışlarımın arkasında yatan hisleri ve tutumları an- 
lamak için kendim hakkında derinlemesine düşünebilirim') yedi madde, (iii) beceri-iletişim kapasitesi ve problem çözme (örn: 'Konuşma strasında konuyu ne zaman değiştireceğimi bilirim') yirmi beş madde ve (iv) katılımonın geçmişi ile ilgili on açık uçlu soru (örn: 'Öğrendiğiniz dil(ler)i ve her birini ne kadar sürede öğrendiğinizi yazınız (Örneğin: Fransızca - 6 ay, İspanyolca 2 yıl). Öğrendiğiniz başka bir dil yok ise lütfen N/A (mevcut değil) olarak işaretleyin') şeklindedir. İk üç bölümde 4'lü likert ölçekli sorulara 1 "Kesinlikle katılmıyorum", 2 "Katılmıyorum", 3 "Katılıyorum" ve 4 "Kesinlikle katılıyorum" şeklinde değerler verilmiştir. KYÖ'de yer alan maddelerden on altısı ters kodlanmaktadır. Ters kodlanan maddelere örnek olarak 'Öğrencilerin tartışmalı konuşan kişileri dinlemelerinin onlar için kafa karıştırıcı ve yanıltıcı olduğuna inanırım' ve 'Zor bir kişisel sorunla karşılaşıldığında, sorunun çözümüne ilişkin diğer insanların tavsiyesine uyulmasındansa tek başına karar verilmesi daha iyidir' verilebilir.

KYÖ, Brantley-Todd (2017), tarafından temel olarak dört aşamayı takip ederek geliştirilmiştir. Ölçek sahibinin yaptı̆̆ işlemler sırasıyla aşağıdaki gibi açıklanmıştır: Birinci aşamada alanyazın taramasıyla bu çalışmanın teorik çerçevesi ile tutarlı göstergeleri vurgulayan küresel yetkinlik özelliklerinin mevcut ölçümlerine dayalı olarak Taslak Ölçek 1 oluşturulmuştur. Taslak Ölçek 1 KYÖ'nün tüm boyutlarını kapsayan (eğilim-duygusal alan, açık fikirlilik; bilgi-kendilik bilgisi; beceri-iletişim kapasitesi ve problem çözme) değişkenlerin yer aldığı alanyazındaki ölçeklerin yazar tarafından uyarlanmasıyla ve yazarın geliştirdiği maddelerin eklenmesiyle oluşturulmuştur. Taslak Ölçek 1 uyarlanan ölçekler ve araştırmacının kendi geliştirdiği maddelerle birlikte dört bölüm ve 137 maddeden oluşmaktadır. İkinci aşamada ilköğretim öğretmen adaylarından oluşan bir örneklemle Taslak Ölçek 1'in pilot araştırmaları yapılarak sonuçlara göre ölçeğin yeniden düzenlenmesiyle Taslak Ölçek 2 elde edilmiştir. Pilot çalışma sonucunda 94 maddelik bir form elde edilmiştir. Üçüncü aşamada KYÖ'nün son halini alabilmesi için Delphi tekniği ile inceleme yapılmış ve KYÖ nihai halini almıştır. Brantley-Todd (2017), küresel yetkinlik konusunda uzmanlaşmış 10 katılımcı ile KYÖ'nün maddelerine son halini vermiştir. Katılımcllar, uluslararası ilişkiler, uluslararası eğitim, küresel eğitim, dünya dilleri eğitimi, küresel sağlık ve eğitim liderliği ile ilgili mesleki veya akademik pozisyonlarda halen çalışan ve emekli bireylerden oluşmuştur. Söz konusu delphi incelemesi birbirini takip eden 3 turdan sonra tamamlanmıştır. 1. Turda ölçek bölümlerinin her birinin mevcut araştırmada tanımlandığı gibi tutu- 
lup tutulmayacağına dair panelist görüşleri istenmiştir. Bir bölümün Taslak Ölçekten çıkarılıp çıkarılmadığını belirlemek için panelistlerin görüşleri arasında \%75'lik bir kesme noktası oluşturulmuştur. Bu tur sonucunda eğilim/duygusal alan, bilgi, beceri ve katılımcı bilgilerini içeren bölümlerin tamamı Taslak Ölçekte kalmıştır. 2. Turun amacı, ölçek bölümlerinin her birinde hangi maddelerin tutulacağını belirlemek olmuştur. 3 . Turun amacı ise kalan maddeler üzerinde fikir birliğine varılıp varılamayacağını belirlemek olmuştur. Delphi incelemesinin sonunda uzman katılımcıların fikir birliği ile KYÖ nihai halini almıştır.

\section{Dil Eşdeğerliği Çalışması}

Araştırmada veri toplamak amacıyla Küresel Yetkinlik Ölçeği'nin Türkçe Formu (KYÖ-TF) kullanılmıştır. KYÖ-TF'nun hazırlanma aşamasında ilk olarak KYÖ'yü geliştiren Brantley-Todd'dan uyarlama izni alınmıştır. İznin alınmasının ardından her iki dile de çok iyi düzeyde hakim üç dil uzmanı tarafından İngilizce dilindeki KYÖ'nün ölçek maddelerinin Türkçe tercümesi yapılmıştır. Elde edilen üç ayrı çeviri formu, her iki dile de iyi düzeyde hakim bir eğitim yönetimi uzman ile birlikte müzakere edilerek, her bir madde için ayrı ayrı olmak üzere, Türk kültürüne en uygun çevrilen ifadeler seçilerek tek bir taslak form elde edilmiştir. Elde edilen bu form eğitim yönetimi, eğitimde ölçme ve değerlendirme, rehberlik ve psikolojik danışma alanlarından uzmanların görüşüne baş vurulmuştur. Maddeler üzerinden gelen geri bildirimlere bağlı kalınarak taslak form üzerinde gerekli düzenlemeler yapılmıştır. Form bu haliyle 15 öğretmen ve 5 okul yöneticisinin görüşüne sunulmuş, anlamsal ve deyimsel yönden ölçeğe nihai hali verilmiştir. İzleyen aşamada Türkçe taslak form ölçeğin Türkçe uyarlama çalışmasında yer almayan başka bir dil uzmanı tarafından ölçeğin orijinal dili olan İngilizce diline geri tercüme edilmiştir. Bu aşamayı takiben geri tercüme sonucunda elde edilen formun özgün form ile eş değerliğini değerlendirmek üzere KYÖ'yü geliştiren Kathryn Todd Bliss'in (University of Kentucky, $\mathrm{ABD}$ ) görüşüne başvurulmuştur. Hak sahibi yazar geri tercüme ile elde dilen ölçek formunun, ölçeğin özgün formu ile dilsel, anlamsal ve kavramsal açıdan büyük ölçüde örtüştügüünü ifade etmiş, ölçeğin bazı maddeleri için kısmi önerilerde bulunmuştur. Yazarın düzeltme önerileri dikkate alınmış, ilgili değişiklikler yapılmış ve revize form tekrar uzmanların görü- 
şüne sunulmuştur. Alan uzmanlarının da onayı ile KYÖ-TF'nin dilsel ve kavramsal açıdan özgün form ile tutarlı olduğuna kanaat getirilmiştir.

\section{İşlemler ve Veri Analizi}

Etik ilkelerin gözetilmesi açısından Hacettepe Üniversitesi'nden Etik Komisyon İzni, 35853172-300 sayı numarası ile ve Ankara İl Milli Eğitim Müdürlüğü'nden Araştırma Uygulama İzni alınıp ilgililere sunulmuştur. Bu kapsamda veri toplama sürecinde katılımcıların gönüllülügü esas alınmıştır ve katılımciların kimlikleri gizli tutulmuştur. Araştırmanın pilot uygulama aşamasında KYÖ, araştırmaya gönüllü olarak katılan 215 öğretmene bizzat uygulanmıştır. Maddelerin yanıtlanması ortalama 8-13 dakika zaman almıştır. Öğretmenler tarafından yanıtlanan ölçekler incelenmiş ve 15 'inin analize uygun şartları taşımadığı belirlenerek bu ölçekler analiz işleminde yer almamıştır. Araştırmanın ana uygulama aşamasında ise 120 öğretmene ölçek bizzat uygulanırken Covid-19 pandemisinin ağırlaşan koşulları nedeniyle 2019-2020 eğitim öğretim yılı bahar döneminde uzaktan eğitime geçildiğinden 304 öğretmenden çevrimiçi veri toplanmıştır. Bu aşamada da geri dönen 18 ölçek veri analizine uygun bulunmamış ve analizlere dahil edilmemiştir. Veriler manipüle edilmeden analiz edilip tarafsızlık ilkesine hassasiyet gösterilmiştir.

KYÖ'nün geçerlik çalışması AFA ve DFA ile; güvenirlik çalışması ise Cronbach's Alfa katsayısı analiziyle yapılmıştır. DFA, daha önceden keşfedilmiş ve tanımlanmış bir yapının, bir model olarak doğrulandığı bir analizdir (Çokluk, Şekercioğlu, Büyüköztürk, 2018, s.275). Başka bir ifadeyle, araştırmacı DFA uygulamasından önce kuramsal bir model kurarak analizi kuramsal bir temele dayalı yürütür (Jöreskog ve Sörbom, 1993; Pituch ve Stevens, 2016). Kuramsal çerçeve doğrultusunda oluşturulmuş dört boyutlu yapı DFA ile incelenmiştir. Bu kapsamda KYÖ'nün faktör yapısının kaynak dilde AFA ile ortaya konulmamış olması nedeniyle ölçeğin yapı geçerliğinin öncelikle pilot çalışma ile hedef dilde AFA ile test edilmesine karar verilmiştir. Analize uygun 200 ölçek üzerinde AFA uygulanmıştır. Faktör sayısının belirlenmesi için yamaç birikinti grafiği (scree plot) ve öz-değer (initial eigen values) sonuçlarından yararlanılmıştır. Maddeleri belirleme sürecinde faktör yükünün minimum 0.30 olması gerektiği ve yüksek iki yük değeri arasındaki farkın minimum 0.10 olması gerektiği ilkesine bakılmıştır (Büyüköz- 
türk, 2020). AFA, Statistical Package for the Social Sciences (SPSS) 22.0 kullan1larak gerçekleştirilmiştir.

İkinci aşama olan ana uygulamada KYÖ'nün kuramsal modeli bir tür hipotez testi olan DFA ile test edilmiştir. Bu aşamada veriler, pilot çalışmada yer almayan, analize uygun 406 katılımcıdan geri dönen ölçeklerden toplanmıştır. DFA neticesinde tespit edilen istatistiksel bulguların değerlendirilmesinde ise alanyazında sıklıkla kabul edilen uyum iyiliği ölçütlerinden yararlanılmıştır. Bu bağlamda çalışmada, ki-kare değerinin, serbestlik derecesine oranı kontrol edilmiştir. Ki-kare değerinin 5 'ten küçük olması orta düzeyde uyumu tanımlarken, 3 'ten küçük olması mükemmel uyumu ifade eder (Kline, 2005; Sümer, 2000). Bunun yanı sıra DFA analizi ile öngörülen modelin veriyi ne ölçüde açıkladığını değerlendirmek amacıyla GFI, NFI, RFI, CFI, S-RMR ve RMSEA uyum iyiliği ölçütlerinden yararlanılmıştır. S$R M R$ değerinin 0.09 'den küçük olması, RMSEA değerinin 0.08 'den küçük olması bununla birlikte GFI, CFI, NFI, değerlerinin 0.90' 1 üzerinde olması, RFI değerinin ise 0.85 'in üstünde olması (Brown, 2006; Schumacher ve Lomax, 2004) bir ölçüt olarak kararlaştırllmıştır. DFA Linear Structural Relations (LISREL) 8.72 yazılımı ile gerçekleştirilmiştir.

Bu çalışmada ölçeğin maddelerinin ne denli ayırt edici olduklarının belirlenmesinde düzeltilmiş madde-toplam korelasyonu analizleri yapılmıştır. KYÖ'nün güvenilirliğini saptamak amaciyla ise Cronbach-Alfa değerleri hesaplanmıştır. Cronbach's Alfa değerleri SPSS 22.0 programı kullanılarak incelenmiştir.

\section{Bulgular}

Araştırmada KYÖ'nün Türk kültüründe geçerli bir ölçme aracı olup olmadığ1 test edilmiştir. Geçerlik çalışmasının ardından KYÖ'nün güvenilir bir ölçme aracı olup olmadığı incelenmiştir.

\section{Geçerliğe İlişkin Bulgular}

KYÖ'nün yapısal geçerliği AFA ve DFA ile araştırılmıştır. İlk aşamada 48 maddeden oluşan ölçek 200 öğretmene uygulanarak pilot uygulama yapılmıştır. Ölçeğin faktör yapısını belirlemek amaciyla toplanan verilere AFA yapılmıştır. Verilerin AFA için uygunluğu Kaiser-Meyer-Olkin (KMO) ve 
Bartlett küresellik testleri incelenmiştir. KMO ve Bartlett küresellik testi testleri, veri dağılımın faktör analizi için uygunluğunu test etmektedir ve $K M O$ sonucunun 0.70-0.80 aralığında olması 'iyi' olarak değerlendirilmektedir (Kalayc1, 2005, s:322). Analizler sonucunda verilerin faktör analizine uygun olduğu gözlenmiştir $(\chi 2=2686.519, p<0.05)$. Bu bulgular 1şığında veri setinin çok değişkenli normal dağılıma sahip olduğu sonucuna varılmıştır (Şencan, 2005).

KYÖ'nün AFA çalışmalarına 48 madde ile başlanmıştır. Faktör sayısının belirlenmesi için yamaç birikinti grafiği (scree plot) ve öz-değer (initial egien values) sonuçlarından faydalanılmıştır. Yapılan faktör analizinde 1 özdeğerinden büyük onbeş faktör, 2 özdeğerinden büyük dört faktör, 3 özdeğerinden büyük iki faktör bulunmuştur. Ölçeğin faktör sayısına karar verme aşamasında özdeğerler grafiği de incelendiğinde baskın düzeyde 2 özdeğerinden büyük, 4 faktör tespit edilmiştir. Dolayısıyla açımlayıc faktör analizi ikinci kez hem 4 faktör ile sınılandırılarak hem de Varimax döndürme işlemi uygulanarak tekrar edilmiştir. Yapılan faktör analizi sonucunda ilk etapta döndürülmüş faktör yükleri değerlendirilmiştir. Ölçek uyarlama ve geliştirme sürecinde faktör yüklerinin 0.30 değerinin altında olmaması gerektiği ve faktörlerin binişik olarak nitelendirilmemesi için yüksek iki yük değeri arasındaki farkın 0.10 'dan yüksek olması gerektiği göz önünde bulundurulmuştur (Büyüköztürk, 2020). Yapılan analizde 9, 15, 16, 23, 32, 35, 39, 40 ve 45 numaralı maddelerin faktör yük değerlerinin 0.30 'dan düşük bulunması; 1 ve 47 numaralı maddelerin de iki faktördeki yük değerleri arasındaki farkın 0.10 'dan düşük bulunması nedeniyle toplam 11 madde ölçekten çıkarılarak faktör analizi üçüncü kez tekrarlanmıştır. 12 numaralı maddenin iki faktördeki yükleri arasındaki farkın 0.10 değerinden düşük bulunması nedeniyle bu madde de ölçekten çıkarılarak kalan 36 madde üzerinden dördüncü kez AFA yapılmıştır. AFA sonucunda KYÖ'nün 4 faktörlü bir yapısı olduğu keşfedilmiştir. Varimax dik döndürme yöntemi ile elde edilen maddelerin döndürülmüş faktör yük değerleri ve hesaplanan düzeltilmiş toplam madde korelasyonları Tablo 2'de, maddelere ait öz-değerler grafiği ise Şekil 1'de sunulmuştur. 


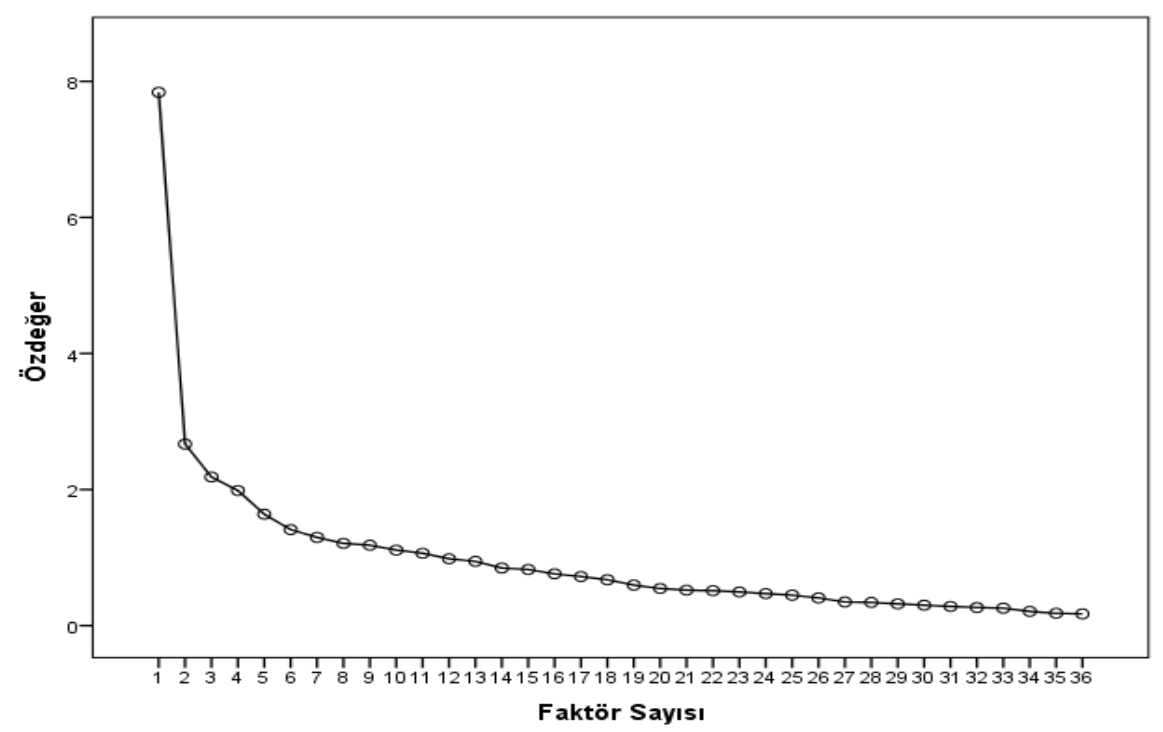

Şekil 1. Öz-değerler Grafiği

Şekil 1'den izleneceği üzere öz-değerlere göre çizilen grafikte birinci faktörden sonra ivmeli bir düşüş belirgindir, bu durum ölçeğin genel bir faktöre sahip olabileceğine işaret etmektedir (Büyüköztürk, 2020, s.143). Öte yandan ivmeli düşüş, daha az olmakla birlikte 2, 3 ve 4 . faktörlerde de devam etmiştir. 5. ve sonraki faktörlerde grafik yatay seyretmekte olup bundan sonraki faktörlerin varyansa olan katkılarının birbirine yakın olduğu sonucuna varılmıştır. 
Tablo 2. Küresel Yetkinlik Ölçeğinin Açımlayıcı Faktör Analizi Sonuçları Döndürülmüş Faktör Yük Değerleri

\begin{tabular}{|c|c|c|c|c|c|}
\hline Maddeler & Fak.1* & Fak.2* & Fak.3* & Fak.4* & nu \\
\hline 26 & .744 & & & & .699 \\
\hline 27 & .737 & & & & .694 \\
\hline 33 & .726 & & & & .689 \\
\hline 28 & .724 & & & & .666 \\
\hline 25 & .713 & & & & .658 \\
\hline 38 & .704 & & & & .655 \\
\hline 34 & .704 & & & & .653 \\
\hline 36 & .674 & & & & .634 \\
\hline 30 & .664 & & & & .626 \\
\hline 37 & .606 & & & & .578 \\
\hline 24 & .589 & & & & .507 \\
\hline 29 & .568 & & & & .473 \\
\hline 17 & & .637 & & & .429 \\
\hline 4 & & .609 & & & .480 \\
\hline 6 & & .571 & & & .422 \\
\hline 22 & & .520 & & & .340 \\
\hline 3 & & .503 & & & .372 \\
\hline 18 & & .486 & & & .330 \\
\hline 8 & & .470 & & & .341 \\
\hline 14 & & .467 & & & .284 \\
\hline 5 & & .446 & & & .377 \\
\hline 2 & & .418 & & & .330 \\
\hline 21 & & & .618 & & .502 \\
\hline 20 & & & .614 & & .558 \\
\hline 19 & & & .599 & & .558 \\
\hline 7 & & & .542 & & .356 \\
\hline 10 & & & .478 & & .313 \\
\hline 31 & & & .477 & & .387 \\
\hline 11 & & & .466 & & .314 \\
\hline 13 & & & .458 & & .304 \\
\hline 44 & & & & .702 & .500 \\
\hline 43 & & & & .695 & .492 \\
\hline 46 & & & & .625 & .445 \\
\hline 42 & & & & .569 & .407 \\
\hline 41 & & & & .545 & .396 \\
\hline 48 & & & & .517 & .387 \\
\hline
\end{tabular}

Öz-değer (Toplam=14.768)

Açılanan Toplam Varyans $=\% 41.021$

$\mathrm{KMO}=.793$

Bartlett küresellik test $=\left(\chi^{2}=2586.519 p<0.01\right)$

"Faktör 1 "İletişim Becerileri"; Faktör 2 "Açık Fikirlilik"; Faktör 3 "Kendilik Biloisi"; Faktör 4 "Problem Çözme Stileri" olarak isimlendirilmiştir.

Tablo 2'den izlendiği üzere kuramsal olarak tanımlanan maddelerin kendi faktörleri altında toplandığı gözlenmiştir. Dört faktörün birlikte açı- 
ladığı varyansın oranı \%41'dir. KYÖ'nün ilk faktörü 12 maddeden oluşmaktadır. Bu faktörün öz-değeri 7.250, tek başına açıkladığı varyansın oranı $\% 16.76$ 'dır. Bu faktör altında konumlanan maddelerin faktör yük değerlerinin 0.74 ile 0.57 arasında değerler aldığı gözlenmiştir. Birinci faktör altında yer alan maddelere örnek olarak "Yeni bir ortama ilk girdiğimde kimin kiminle konuştuğunu gözlemlerim." ve "Konuşma sırasında diğer kişilerin, söylediklerime ne tepki verdiklerine dikkat ederim." verilebilir. Bu faktör altında yer alan maddeler incelenerek faktör "iletişim becerileri" olarak isimlendirilmiştir. Tablo 2'den takip edilebileceği gibi KYÖ'nün ikinci faktörü on maddeden oluşmaktadır. Bu faktörün öz-değeri 3.181; tek başına açıkladığı varyansın oranı \% 8.45'dir. Bu faktör altında konumlanan maddelerin faktör yük değerleri 0.64 ile 0.42 arasındadır. İkinci faktörün altında konumlanan maddelere örnek olarak "Neredeyse her şey için pek çok yanlış, fakat tek bir doğru yolun olduğunu düşünürüm (ters madde)" ve "Değişen dünyanın ihtiyaçlarmı yansıtmaları için kanunların ve sosyal politikaların değişmesi gerektiğine inanırı" verilebilir. Bu faktör altında yer alan diğer maddeler incelenerek, faktör " açık fikirlilik" olarak isimlendirilmiştir.

Tablo 2'den takip edilebileceği gibi KYÖ'nün üçüncü faktörü 8 maddeden oluşmaktadır. Bu faktörün öz-değeri 2.227, tek başına açıkladığı varyansın oran $\% 8.45$ dir. Bu faktör altında konumlanmış maddelerin faktör yükleri 0.62 ile 0.46 arasındadır. Üçüncü faktör altında yer alan maddelere örnek olarak "Kendim hakkında derinlemesine düşünürken hayatta gerçekten ne istediğimi keşfedebilirim" ve "Geçmişte kendimle ilgili öğrendiklerim zorlu durumlara daha iyi karşılık vermemi sağladı." verilebilir. Bu faktör altında yer alan diğer maddelerin de incelenmesiyle bu faktör "kendilik bilgisi" olarak adlandırılmıştır.

Son olarak Tablo 2'den takip edilebileceği gibi KYÖ'nün dördüncü faktörü 6 maddeden oluşmaktadır. Bu faktörün öz-değeri 2.110, tek başına açıkladığı varyansın oranı \%7.38'dir. Bu faktör altında konumlanmış maddelerin faktör yükleri 0.70 ile 0.52 arasındadır. Dördüncü faktör altında yer alan maddelere örnek olarak "Zor bir kişisel sorunla karşılaşıldığında, sorunun çözümüne ilişkin diğer insanlarm tavsiyesine uyulmasındansa tek başına karar verilmesi daha iyidir" ve "Önemli kararlar verirken insanların tavsiyelerine değer veririm." verilebilir. Diğer maddelerin de incelenmesiyle bu faktör "problem çözme stilleri" olarak adlandırılmıştır. 
Tablo 2'de görüldüğü üzere maddelerin, ölçtükleri özellikler açısından, bireyleri ne düzeyde ayırt ettiğini saptamak amaciyla düzeltilmiş madde toplam korelasyonları hesaplanmıştır. Böylece maddelerin her birinden alınan puan ile testin tamamından alınan puan arasındaki ilişki ortaya konulmuştur.

KYÖ ölçeğinin dört faktörlü yapısı çalışmanın ikinci aşaması olan ana uygulamada, DFA ile incelenmiştir. Verilerin çoklu normallik varsayımının reddedilmesi sonucunda Ağırlkklandırlmamış Enküu̧cük Kareler (Robust Unweighted Least Squares-ULS) yöntemiyle Asimtotik kovaryans matrisi kullanılarak parametre kestirimi yapılmıştır. Yapılan analizde 1.faktordeki 26 ve 28 numaralı maddelerin; 2.faktorde 31 ve 21.maddelerin ölçülen yapıyla ilişkisi anlamlı bulunamamıştır. Dolayısıyla bu 4 madde çıkarılarak DFA ikinci kez tekrarlanmıştır. DFA sonuçlarına göre 32 maddenin $t$ değerleri anlamlıdır. $(p<0.05)$. Faktör yüklerinin 0.23 ile 0.82 arasında değiştiği gözlemlenmiştir. 406 kişilik verilere göre dört faktörlü 32 maddelik ölçeğin ölçek maddelerin faktör yük değerlerine ilişkin yol grafiği (Faktör yükleri) Şekil 2'de gösterilmiştir.

Tablo 3. Ölçek Maddelerinin Faktör Yapısı İçin Uyum İyilik İndeksleri

\begin{tabular}{lll}
\hline İyilik Uyum İndeksi & Kabul Edilebilir Sınır * & Değer \\
\hline$X^{2} /$ sd & $<5$ Orta düzeyde & $1365,65 / 458=2,98$ \\
GFI & $<3$ İyi uyum & 0,91 \\
CFI & $>0.90$ & 1,00 \\
NFI & $>0.90$ & 0,97 \\
RFI & $>0.90$ & 0,97 \\
S-RMR & $>0.85$ & 0,091 \\
RMSEA & $<0.09$ & 0,07 \\
\hline
\end{tabular}

Kaynaklar: Kline, 2005; Baumgartner and Homburg, 1996; Bentler, 1980

Tablo 3'e göre benzerlik oran $k i$-kare istatistiği $X^{2}(364)=1021,00 p<0.01 ; K i-$ kare istatistiğinin serbestlik derecesine oranı $\left(X^{2} / s d\right)=2,98$; kök ortalama kare yaklaşım hatası (RMSEA)=0.070; standardize edilmiş kök ortalama kare artık (S$R M R)=0.091$; karşılaştırmalı uyum endeksi $(C F I)=1,00$; uyum iyiliği indeksi $(G F I)=$ 0,91; normlanmış uyum endeksi (NFI)=0,97; göreli uyum endeksi(RFI)=0,97 şeklinde bulunmuştur. Uyum indekslerinin kabul edilebilir değerlerin üstünde olduğu bulunmuştur. Böylece dört faktörlü 32 maddelik ölçeğin yapısal geçerliliği kabul edilmiştir. 


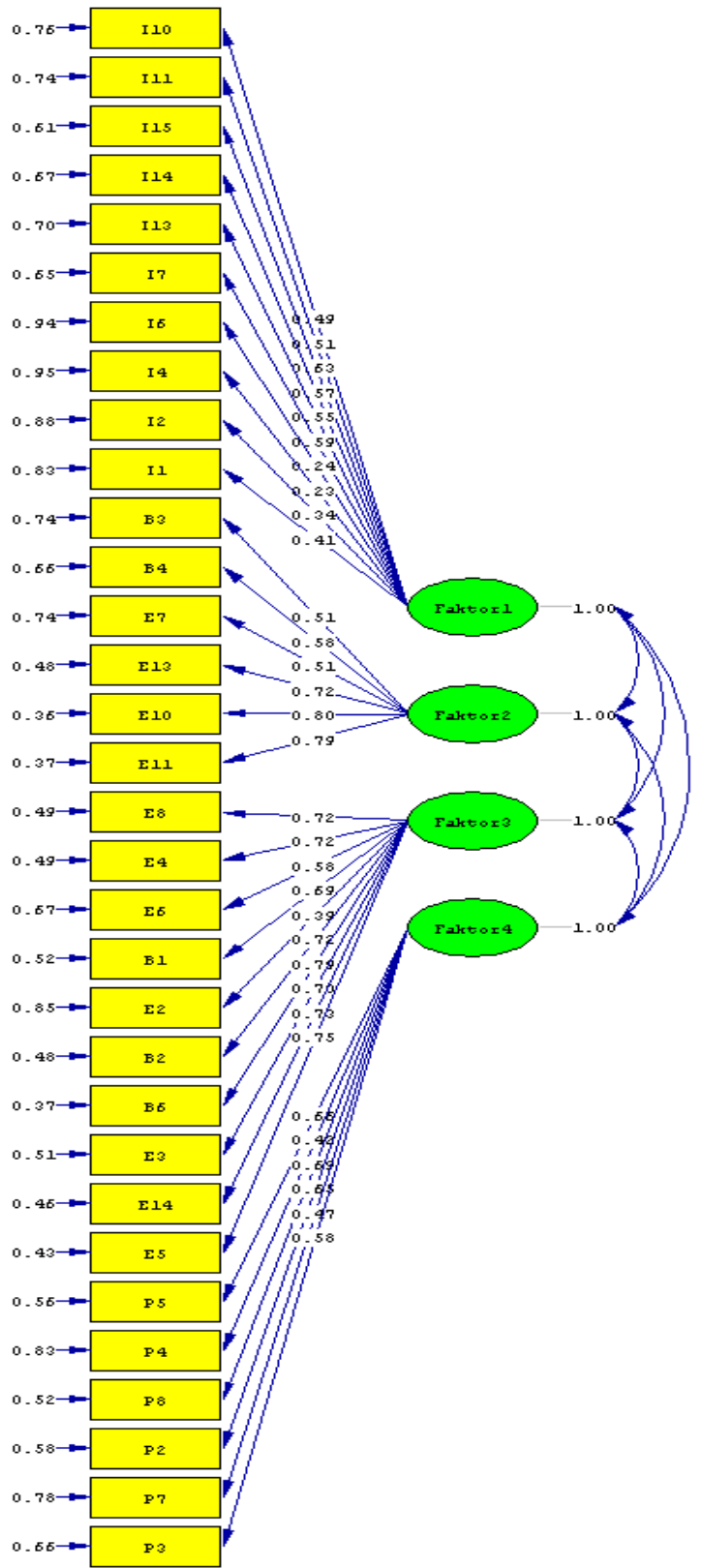

Chi-Square=1365.65, df=458, P-value=0.00000, RMSEA $=0.070$

Şekil 2. KYÖ Maddeleri Yol (Path) Grafiği 


\section{Güvenirliğe İlişkin Bulgular}

KYÖ'nün güvenirliği Cronbach's Alfa katsayısı ile hesaplanmıştır. Güvenirlik katsayısı, 0 ile +1 arasında değerler alırken, güvenirlik kat sayısının 1'e yakın değerler aldığı durumda ölçeğin güvenirliğinin yüksek olduğu, maddeler arasındaki iç tutarlılığın da yüksek olduğu sonucuna varılır. Sonuçlar Tablo 4'te sunulmuştur.

Tablo 4. KYÖ Güvenirlik Analizi

\begin{tabular}{|c|c|c|c|c|}
\hline Ölçek ve Faktörler & Aşama & $\begin{array}{l}\text { Katılıma } \\
\text { Sayıları }\end{array}$ & Madde Sayısı & $\begin{array}{l}\text { Cronbach's Alpha } \\
\text { Değer }\end{array}$ \\
\hline İletişim becerileri & & & & .902 \\
\hline & & & 12 & \\
\hline Açık fikirlilik & Pilot Uygulama & & 10 & .710 \\
\hline \multirow[t]{2}{*}{ Kendilik bilgisi } & & 200 & & .715 \\
\hline & & & 8 & \\
\hline Problem Çözme Stilleri & & & 6 & .704 \\
\hline KYÖ (Tümü) & & & 36 & .804 \\
\hline \multirow[t]{2}{*}{ İletişim becerileri } & & & & .896 \\
\hline & & & 10 & \\
\hline Açık fikirlilik & Ana Uygulama & & 10 & .775 \\
\hline \multirow[t]{2}{*}{ Kendilik bilgisi } & & 406 & & .670 \\
\hline & & & 6 & \\
\hline Problem Çözme Stilleri. & & & 6 & .730 \\
\hline KYÖ (Tümü) & & & 32 & .820 \\
\hline
\end{tabular}

Tablo 4'te görüldüğü üzere çalışmanın her iki aşamasında da hesaplanan güvenirlik katsayıları Cronbach's Alfa cinsinden güvenirlik katsayısı pilot uygulama aşamasında iletişim becerileri faktörü için .902; açık fikirlilik faktörü için .710; kendilik bilgisi faktörü için .715; problem çözme stilleri faktörü için .704 ve KYÖ'nün tamamı için .804 olmuştur. Çalışmanın ana uygulama aşamasında ise Cronbach's Alfa cinsinden güvenirlik katsayısı iletişim becerileri faktörü için .896; açık fikirlilik faktörü için .775; kendilik bilgisi faktörü için .670; problem çözme stilleri faktörü için .730 ve KYÖ'nün tamamı için .820 olmuştur. Bu sonuçlar KYÖ'nün güvenilir bir ölçek olduğunu göstermektedir (Balcı, 2005).

\section{Tartışma, Sonuç ve Öneriler}

$\mathrm{Bu}$ çalışma, küresel yetkinlik kavramını öğretmen görüşleriyle ölçmeye yarayacak geçerli ve güvenilir bir ölçme aracını elde etmek amacıyla yapıl- 
mıştır. Bu bağlamda orjinali Brantley-Todd (2017) tarafından geliştirilen Küresel Yetkinlik Ölçeği'nin Türk kültürüne uyarlanmasının geçerlik ve güvenirlik araştırmaları yapılmıştır. KYÖ'nün Türk kültürüne uyarlama çalışmasına dil eşdeğerliği çalışmaları ile başlamıştır. Dil uzmanları, alan uzmanları, akademisyenler, öğretmen ve okul yöneticileri ile ölçeğin geliştiricisinin tekrarlı geri bildirimleri sonunda ölçeğin dil eşdeğerliği sağlanmış ve Türkçe formu elde edilmiştir. Ardından çalışma iki ayrı örneklemle iki aşamada gerçekleştirilmiştir. Ölçeğin faktör yapısının kaynak dilde AFA ile belirlenmemiş olması nedeniyle pilot uygulamada KYÖ ölçeğinin faktör yapısı AFA işlemleriyle keşfedilmiş, ana uygulamada ise DFA işlemleriyle KYÖ'nün yapı geçerliği incelenmiştir.

Çalışmanın pilot aşamasında verilerin AFA için uygunluğu Kaiser-MeyerOlkin (KMO) ve Bartlett küresellik testleri incelenmiştir. Bu testlerin sonuçları ile veri setinin çok değişkenli normal dağılıma sahip olduğu bulgusuna ve faktör analizi için veri setinin uygun olduğu genel sonucuna ulaşılmıştır. Ardından gerçekleştirilen AFA analizi KYÖ'yü oluşturan maddelerinin dört boyut altında toplandığını göstermiştir. Bu bulgu ölçeği geliştiren BrantleyTodd'un (2017) ön görmüş olduğu sonuçla uyumludur. Söz konusu boyutlar iletişim becerileri, bilgi-kendilik bilgisi, açık fikirlilik ve problem çözme stillerinden oluşmaktadır. Pilot aşamanın tamamlanmasının ardından ana uygulamaya geçilmiştir. Bu aşamada veri setinin çoklu normallik varsayımının reddedilmesi sonucunda Ağırlıklandırlmamış Enküçük Kareler (Robust Unweighted Least Squares-ULS) yöntemiyle Asimtotik kovaryans matrisi ile parametre kestirimi yapılmıştır. Çalışmanın ana uygulama kısmındaki DFA analizi sonucunda elde edilen yol grafiği ve uyum iyiliği değerleri KYÖ'nün kuramsal yapı ile iyi derecede uyuma sahip olduğunu ve ölçeğin model geçerliğinin sağlandığını göstermiştir. Alanyazında küresel yetkinlik kavramının bir hayat boyu öğrenme hedefi olarak ele alınması gerektiği ve kavramın farklı boyutlardan oluştuğuna dikkat çeken çalışmalar mevcuttur (Hanvey, 1976; Kniep 1989; O'Loughlin ve Wegimont, 2002; Kagan ve Stewart 2004a, Bennet, 2004; Kagan ve Stewart 2004b, Stewart, 2005, Wagner, 2008, DarlingHammond, 2010, Boix-Mansilla ve Jackson, 2011; Mansilla, 2017; Schleicher, 2017; OECD, 2018). Küresel yetkinliğin boyutları olarak da bilgi ve beraberinde eleştirel düşünme, (Buckingham, 2007; Kellner and Share, 2005) açık fikirlilik (Fennes and Hapgood, 1997), iletişim becerileri ve problem çözme stillerinden (Barrett, Byram, Lazar, Mompoint-Gaillard ve Philippou, 2013) 
söz edilmektedir. Bu doğrultuda Uluslararası Öğrenci Değerlendirme Programı (PISA), Küresel yetkinliği ilk olarak 2018 yılında ölçmek ve değerlendirmek üzere sınav kapsamına aldığında söz konusu kavram "küresel ve kültürlerarası meseleleri eleştirel olarak ve farklı açlardan çözümleme, farklılıkların kişinin ve başkalarının algılarını, yargılarını ve düşüncelerini nasıl etkilediğini anlama ve farklı kültürlere sahip başkalarıyla insan onuruna duyulan ortak saygı temelinde açı, uygun ve etkili iletişime geçebilme kapasitesi" olarak tanımlanmıştır (OECD, 2018). Bu tanım, bireylerin günlük yaşamlarında başarılı bir şekilde sürdürmeleri gereken küresel yetkinliğin dört hedef boyutunu özetlemektedir.

Maddelerin ayırt ediciliklerinin tespiti için madde toplam korelasyon değerleri hesaplanmıştır. Ayrıca KYÖ'nün tamamı ve boyutları için çalışmanın her iki aşamasında da iç tutarlılıklar, Cronbach's Alpha katsayısının hesaplanması ile değerlendirilmiştir. Güvenirlik analizleri, KYÖ'nün madde ayırt ediciliğinin ve iç tutarlığının yeterli düzeyde olduğunu göstermiştir. Güvenirlik analizleri bulguları alanyazında Cronbach's Alpha katsayısının yorumlanması üzerinde bu değerin .60 ile .70 arasında olmasının kabul edilebilir olduğunu, 70 ve üstünün iyi düzeyde yorumlanabileceğini (Özdamar, 2002; Büyüköztürk, 2020); .61 ile .80 arası değerin oldukça yeterli düzeyde güvenirliğe işaret ettiğini (George ve Mallery, 2003; Terzi, 2017) ifade eden çalışmalarla uyumludur.

Bu araştırmada Brantley-Todd'un (2017) geliştirdiği KYÖ'nün Türk kültüründe öğretmenlerin görüşleriyle küresel yetkinlik kavramı ölçülmesine elverişli ve güvenilir olduğu sonucuna ulaşılmıştır. Uluslararası alanyazında da görece yeni olan bu kavramı eğitim bağlamında ele alarak bir ölçme aracı geliştiren ya da uyarlayan bir çalışmaya rastlanmamıştır. Bu durum mevcut çalışmayı özgün kılmaktadır. Ancak KYÖ'nün Türk kültürüne uyarlanmasını içeren bu araştırma bazı sınırlılıklara sahiptir. Özellikle veri toplama süreci Covid-19 pandemi döneminde gerçekleşmiş, bu durum yüz yüze veri toplanması imkanlarını sınırlamıştır. Bu nedenle gelecek araştırmalarda daha geniş örneklemlerle KYÖ'nün geçerliği ve güvenirliğinin test edilmesi önerilebilir. Ayrıca öğretmenlerin küresel yetkinlikleri ve okul yöneticisi yeterlikleri arasındaki ilişkilerin araştırılması alanyazına katkılar sağlayabilir. 


\title{
EXTENDED ABSTRACT Turkish Adaptation Study of the Global Competence Scale \\ *
}

\author{
Cansu Karaca Akarsu- Murat Özdemir \\ Bahçeşehir School - Hacettepe University
}

In 2015, 193 member countries of the United Nations unanimously accepted the Sustainable Development Goals, which aim to end poverty, combat inequalities and protect the environment. With the idea that education is the most powerful tool to create a more just, more inclusive world that works for the common good of humanity; Goal 4, which focuses on quality education for all, consciously emphasized the learning of a sustainable common life as well as basic knowledge and skills such as literacy, mathematics and science. (Schleicher, 2017). In this direction, the International Student Assessment Program (PISA) has included an examination to measure and evaluate global competence for the first time in 2018 (OECD, 2018).

PISA's global competency assessment provides countries with the data they need to create more sustainable societies through education. While the term global competence has many connections with ideas presented in the 20th century regarding international research and global education, it was hardly used before 2011. The Asian Community has used the term 'global competence' for its International Schools Network (BoixMansilla and Jackson, 2011). Boix-Mansilla and Jackson (2011) introduce and elaborate this concept and provide the rationale for integrating global competence strategies into the high school curriculum.

Global competence can be developed in many contexts, but schools have a vital role to play. Schools can offer young people opportunities to critically examine meaningful developments in both the world at large and their own lives (Bennet, 2004). It can teach them how to use digital information, social media platforms critically and with a sense of responsibility (Buckingham, 2007). Teachers can encourage intercultural sensitivity and respect by encouraging students to gain experiences by communicating with different cultures (OECD, 2018; OECD, 2018a). 
However, many teachers and school leaders do not have prior training in instilling global competence in their curricula. In addition, most teachers do not include or emphasize global awareness or global competence in their curricula (Cushner and Brennan cited in Felch, 2016).

It is important to investigate the concept of global competence, which is closely related to many concepts such as global education, 21st century skills, teacher competence, and self-efficacy. However, there is no measurement tool developed by Turkish researchers on this subject. Brantley-Todd (2017), for the first time in the sources accessed, developed an assessment-evaluation tool by addressing the concept of global competence, which is a new concept in international literature, in the context of education. The Global Competence Scale developed by Brantley-Todd (2017) consists of 48 items covering four dimensions of the integrated structure for global competence. In this context, the rationale of the present study is to test the validity and reliability of the Global Competence Scale in Turkish culture and thus adapt the scale to Turkish. Turkey in the context of the global competency examination in a synchronized manner with the international literature and Turkish adaptation of the scale of the data collection process can contribute to the scientists to do research on global competencies.

Purpose: In this context, the aim of the study is to adapt the Global Competence Scale developed by Brantley-Todd (2017) to Turkish and to test the validity and reliability of the scale based on teacher data. The following questions were sought in the study;

- Is Global Competence Scale a valid data collection tool in Turkish culture?

- Is Global Competence Survey a reliable data collection tool in Turkish culture?

Methods: Survey design was used in the research. In this direction, descriptive method was applied and quantitative research techniques were used. Research data were obtained from teachers working in the central districts of Ankara in the second term of the 2019-2020 academic year. The study was carried out in two stages with two different study groups. The pilot study, which is the first phase, was carried out with a total of 
200 teachers working in public and private secondary education institutions in Ankara in the second term of the 2019-2020 academic year. In the second phase which is the the main implementation, a study was carried out with 406 teachers working in public secondary education institutions in nine central districts of Ankara in the second term of the 2019-2020 academic year. The Turkish Form of the Global Competence Scale (GCS) was used to collect data in the study.

Requirred legal permissions have been obtained in order to conduct the research. In this context, the volunteering of the participants was taken as a basis in the data collection process and the identities of the participants were kept confidential. In the pilot implementation phase of the study, the GCS was personally applied to 215 teachers who participated in the study voluntarily. Response of the scale items took 8-13 minutes on average. In the main application phase of the study, while the scale was applied to 120 teachers personally, online data were collected from 304 teachers as face-to-face data collection was not possible due to the worsening conditions of the pandemic.

Validity study of GCS was carried out with EFA and DFA whereas the reliability study was carried out with Cronbach's Alpha coefficient analysis. CFA is an analysis that tests whether a previously discovered and defined structure is verified as a model (Çokluk, Şekercioğlu, Büyüköztürk, 2018, p. 275). In this context, it was decided to test the construct validity of the scale with EFA in the target language with a pilot study, since the factor structure of the GCS was not revealed in the source language with EFA. EFA was applied on 200 scales suitable for analysis. In order to determine the number of factors, scree plot and initial eigen values results were used. In the process of determining the items, the principle that the factor load should be at least 0.30 and the difference between the two high load values should be at least 0.10 (Büyüköztürk, 2020). AFA was performed using the Statistical Package for the Social Sciences (SPSS) 22.0.

In the second stage, the main application, the theoretical model of GCS was tested with CFA, a kind of hypothesis test. At this stage, the data were obtained from the scales returned from 406 participants who were not included in the pilot study and were suitable for analysis. In the evaluation of the statistical results observed as a result of CFA, some 
goodness of fit criteria accepted in the literature were used. For this purpose, the ratio of the chi-square value to the degrees of freedom was examined in the study. Apart from that, in order to evaluate the suitability of the proposed model within the scope of CFA, harmony statistics such as RMSEA and GFI, NFI, RFI, CFI, S-RMR were used. DFA was performed using Linear Structural Relations (LISREL) 8.72.

Findings: As a result of EFA analysis, it is found that the theoretically defined items are gathered under their own factors. The total variance explained by the four factors together is $41 \%$. The first factor of GCS includes 12 items. The eigen-value of this factor has been calculated as 7.250 . The variance explained by this factor alone is $16.76 \%$. It is seen that the factor loading values of the items under this factor vary between 0.74 and 0.57 . The second factor of GCS includes ten items. The eigenvalue of this factor has been calculated as 3.181. The variance explained by this factor alone is $8.45 \%$. The factor load values of the items under this factor vary between 0.64 and 0.42 . The third factor of GCS includes 8 items. The eigenvalue of this factor has been calculated as 2.227 . The variance explained by this factor alone is $8.45 \%$. The factor load values of the items under this factor vary between 0.62 and 0.46 . The fourth factor of GCS contains 6 items. The eigenvalue of this factor has been calculated as 2.110. The variance explained by this factor alone is $7.38 \%$. The factor load values of the items under this factor vary between 0.70 and 0.52 . As a result of EFA analysis, the 4-factor structure of the scale named as communication skills, open-mindedness, self-knowledge and problem solving styles was confirmed

According to the CFA results, $t$ values of 32 items are found to be significant $(\mathrm{p}<0.05)$. In other words, there is no need to remove any item from the scale at this stage. It is observed that the factor loadings varied between 0.23 and 0.82 . Obtained several fit indices to evaluate the model fit; similarity ratio chi-square statistic $X^{2}(364)=1021.00 p<0.01$; The ratio of chi-square statistics to degree of freedom $\left(X^{2} / \mathrm{sd}\right)=2.98$; root mean square error of approximation $(R M S E A)=0.070$; standardized root mean square residuals $(S-R M R)=0.091$; comparative fit index $(C F I)=1.00$; goodness of fit index $(G F I)=0.91$; normed fit index $(N F I)=0.97$; the relative fit index $(R F I)$ was 
calculated as $=0.97$. Fit indices are found to be above acceptable values. Thus, the structural validity of the four-factor 32-item scale is accepted.

Reliability of GCS was calculated by Cronbach's Alpha coefficient. Cronbach's Alpha value was .902 for the communication skills factor in the pilot application phase; .710 for the open-mindedness factor; .715 for the self-knowledge factor; .704 for the problem-solving styles factor and .804 for the whole scale. In the main application phase of the study, the reliability coefficient in Cronbach's Alpha for the communication skills factor was .896 ; .775 for the open-mindedness factor; .670 for the selfknowledge factor; .730 for the problem-solving styles factor and .820 for the entire scale. These results show that the GCS is a reliable scale (Balcl, 2005).

Discussion, Conclusion, Suggestions: This study was carried out in order to obtain a valid and reliable measurement tool that will help to measure the concept of global competence with teachers' opinions. In this context, validity and reliability studies of the adaptation of the Global Competence Scale, originally developed by Brantley-Todd (2017), to Turkish culture have been conducted. The adaptation study of GCS to Turkish culture has been started first with language equivalence studies. Language equivalence of the scale was achieved and the Turkish form was obtained as a result of repeated feedback from language experts, field experts, academicians, teachers and school administrators and the developer of the scale. Then the study was carried out in two stages with two separate samples. Since the factor structure of the scale was not determined by EFA in the source language, the factor structure of the GCS scale was discovered with EFA processes in the pilot application, and the structure validity of the GCS was tested with CFA procedures in the main application.

As a result of this study it can be said that the GCS developed by Brantley-Todd (2017) is convenient and reliable for measuring the concept of global competence with the opinions of teachers in Turkish culture. In the international literature, there is no study that develops or adapts a measurement tool by considering this relatively new concept in the context of education, which is the fact that makes the current study unique. However, this study, which includes the adaptation of GCS to 
Turkish culture, has some limitations. In particular, the data collection process took place during the covid-19 pandemic period, which limited the possibilities of face-to-face data collection. For this reason, it may be suggested to test the validity and reliability of GCS with larger samples in future studies. In addition, researching the relationships between teachers' global competencies and school administrator competencies may contribute to the literature.

\section{Kaynakça / References}

Adler, N.J. and Bartholomew, S. (1992). Managing globally competent people. The Executive, 6, 52-65. https://doi.org/10.5465/ame.1992.4274189.

American Council on Education (ACE). Commission on International Education. (1998). Educating for global competence: America's passport to the future. The Council. https://files.eric.ed.gov/fulltext/ED421940.pdf 18.06.2020.

Baumgartner, H. and Homburg, C. (1996). Applications of structural equation modeling in marketing and consumer research: A review. International Journal of Research in Marketing, 13(2), 139-161. https://doi.org/10.1016/01678116(95)00038-0.

Balcı, A. (2005). Sosyal bilimlerde araştırma: Yöntem, teknik ve ilkeler. Ankara:Pegem.

Barrett, M., Byram, M., Lázár, I., Mompoint-Gaillard, P. and S. Philippou (2013), Developing intercultural competence through education. Council of Europe Publishing.https://rm.coe.int/developing-intercultural-enfr/16808ce258 20.06.2020.

Bennett, M. J. (2004). Becoming interculturally competent. Wurzel, J. (Ed.) Toward multiculturalism: A reader in multicultural education (2.nd ed. s. 62-77). Newton. MA: Intercultural Resource Corporation. https://www.una.org/sites/livenew.uua.org/files/becoming interculturally competent 3.pdf 10.05.2020.

Bentler, P.M. (1980). Multivariate analysis with latent variables: Causal modeling. Annual Review of Psychology, 31, 419-456. https://doi.org/10.1146/annurev.ps.31.020180.002223.

Boix-Mansilla, V. and Jackson, A. (2011). Educating for global competence: Learning redefined for an interconnected world. Asia Society. https://asiasociety.org/files/chapter2.pdf 13.04.2020.

Boix-Mansilla, V. and Jackson, A. (2012). Educating for global competence: Preparing our youth to engage the world. Council of Chief State School Officers https://doi.org/10.13140/2.1.3845.1529. 
Brantley-Todd, K. (2017). Global competence survey development. (Doctoral dissertation). University of Kentucky. Theses and Dissertations--Education Science. 29. http://uknowledge.uky.edu/edsc etds/29 02.02.2020.

Brown, T.A. (2006). Confirmatory factor analysis for applied research. New York: Guilford.

Buckingham, D. (2007). Digital Media Literacies: rethinking media education in the age of the internet. Research in Comparative and International Education, 2(1), 43-55. https://doi.org/10.2304\%2Frcie.2007.2.1.43.

Büyüköztürk, Ş., Kılıç Çakmak, E., Akgün, Ö.E., Karadeniz, Ş. ve Demirel, F. (2013). Bilimsel araştırma yöntemleri (14. bs.). Ankara:Pegem.

Büyüköztürk, Ş. (2020). Sosyal ilimler için veri analizi kitabı: İstatistik, araştırma deseni, SPSS uygulamalar ve yorum (27.bs). Ankara: Pegem.

Council of Europe (2016). Competences for democratic culture: Living together as equals in culturally diverse democratic societies. Strasbourg: Council of Europe. https://rm.coe.int/16806ccc07 15.04.2020.

Council on International Educational Exchange (CIEE). (1993). Educating for global competence: The report of the Advisory Council for International Educational Exchange. The Council. https://files.eric.ed.gov/fulltext/ED368275.pdf 15.04.2020.

Çokluk, Ö., Şekercioğlu, G., Büyüköztürk, Ş. (2018). Sosyal bilimler için çok değişkenli istatistik SPSS ve LISREL uygulamaları. Ankara: Pegem

Darling-Hammond, L. (2010). America's commitment to equity will determine our future. Phi Delta Kappan, 9(14), 8-14. https://doi.org/10.1177\%2F003172171009100403.

Felch, C. (2016). Preparing the next generation of global leaders: How principals in international studies high schools promote global competence (Order No. 10195984). ProQuest Dissertations \& Theses Global. (1868504912). https://search.proquest.com/dissertations-theses/preparing-next-generation-globalleaders-how/docview/1868504912/se-2?accountid=11248 06.03.2020.

Fennes, H., K. Hapgood (1997). Intercultural learning in the classroom: crossing borders. London: Cassell.

Friedman, T. L. (2005). It's a flat world, after all. The New York Times, 3, 33-37. https://www.nytimes.com/2005/04/03/magazine/its-a-flat-world-afterall.html 02.09.2020.

Gaudelli, W. and Fernekes, W. R. (2004). Teaching about global human rights for global citizenship. The Social Studies, 95(1), 16-26. https://doi.org/10.3200/TSSS.95.1.16-26. 
George, D., Mallery, P. (2003). SPSS for Windows step by step: A simple guide and reference 11.0 update (4th ed.). Boston: Allyn \& Bacon.

Global partnership. (2019). The GPE Results report. https://www.globalpartnership.org/content/results-report-2019 20.04.2020

Hanvey, R.G., (1976). An attainable global perspective. Center for War/Peace Studies. https://eric.ed.gov/?id=ED116993 28.08.2020.

Hersi, A. A. (2010). Darling-Hammond: The flat world and education: How America's commitment to equity will determine our future. Journal of Educational Change, 11, 291-295 https://doi.org/10.1007/s10833-010-9137-7.

Holton, R. (2000). Globalization's cultural consequences. The Annals of the American Academy of Political and Social Science, 570(1), 140-152. https://doi.org/10.1177\%2F000271620057000111.

Hunter, B., White, G. P. and Godbey, G. (2006). What does it mean to be globally competent? Journal of Studies in International Education, 10(3), 267-285. https://doi.org/10.1177\%2F1028315306286930.

International Baccalaureate Organization (IBO). (2012). IB Answers. What is international mindedness?

https://ibanswers.ibo.org/app/answers/detail/a_id/3341/ /whatisinternational-mindedness\%3F on October 24, 2012 20.04.2020.

Jöreskog, K. G. and Sörbom, D. (1993). LISREL 8: Structural equation modeling with the SIMPLIS command language. Scientific Software International.

Kagan, S.L. and Stewart, V. (2004a). International education in the schools: The state of the field. Phi Delta Kappan, 86(3), 229-241. https://doi.org/10.1177\%2F003172170408600312.

Kagan, S.L. and Stewart, V. (2004b). Putting the world into world-class education: Introduction.Phi Delta Kappan, 86(3), 195-196. https://doi.org/10.1177\%2F003172170408600305.

Kalayc1, Ş. (2005). SPSS Uygulamal çok değişkenli istatistik teknikleri. Ankara: Asil Yayın Dağıtım.

Kellner, D. and J. Share (2005). Toward Critical Media Literacy: Core concepts, debates, organizations, and policy. Discourse Studies in the Cultural Politics of Education, 26(3), 369-386. https://doi.org/10.1080/01596300500200169.

Kline, R. B. (2005). Principles and practice of structural equation modeling. New York: Guilford.

Mansilla, V. B. and Gardner, H. (2007). From teaching globalization to nurturing global consciousness. Suárez-Orozco (Ed), Learning in the global era: ınterna- 
tional perspectives on globalization and education (s. 58). University of California Press.

Organisation for Economic Co-operation and Development (OECD). (2018). Preparing our youth to an inclusive and sustainable world. The OECD PISA Global Competence Framework. https://www.oecd.org/education/Globalcompetency-for-an-inclusive-world.pdf 10.03.2020.

Organisation for Economic Co-operation and Development (OECD). (2018a). World Class- How to build a 21st-century school system, strong gerformers and successful reformers in education. Paris: OECD Puplishing.

O'Loughlin, E., Wegimont, L. (Ed.) (2002). Global education in Europe to 2015: Strategy, policies and perspectives. $h$ ttps://rm.coe.int/168070f089 01.06.2020.

Özdamar, K. (2002). Paket programlarda istatistiksel veri analizi-1 (4. bs). Kaan Kitabevi

Patton, M.Q. (2005). Qualitative research. New York: John Wiley and Sons.

Pituch, K. A. and Stevens, J. P. (2016). Applied multivariate statistics for the social sciences: Analyses with SAS and IBM's SPSS (6th ed.). Routledge.

Reimers, F. (2009). Global competency is imperative for global success. Chronicle of Higher Education, 55(21), A29. https://www.chronicle.com/article/globalcompetency-is-imperative-for-global-success/ 14.02.2020.

Schumacher, R. and Lomax, R. (2004). A beginner's guide to structual equation modelling. London: Lawrence Erlbaum Associates.

Sinicrope, C., Norris, J. and Watanabe, Y. (2007). Understanding and assessing intercultural competence: A summary of theory, research, and practice (technical report for the foreign language program evaluation project). University of Hawai'I Second Langauge Studies Paper, 26(1), 1-58.

Schleicher, A. (2017, Aralık). Educating our youth to care about each other and the world. https://oecdedutoday.com/educating-our-youth-to-care-about-each-other-and-theworld/ 12.06.2020.

Stewart, V. (2005). A world transformed: How other countries are preparing students for the interconnected world of the 21st century. Phi Delta Kappan, 87(3), 229-232 https://doi.org/10.1177\%2F003172170508700316.

Sümer, N. (2000). Yapisal eşitlik modelleri: Temel kavramlar ve örnek uygulamalar [Structural equation modeling: Basic concepts and applications]. Türk Psikoloji Yazilari, 3(6), 49-74.

Şencan, H. (2005). Sosyal ve davranışsal ölçümlerde güvenirlik ve geçerlik. Seçkin.

Tabachnick, B. G. and Fidell, L. S. (2012). Using multivariate statistics (6th ed.). Boston: Allyn \& Bacon. 
Terzi, Y. (2017). Güvenirlik analizi ders notları. Ondokuz Mayı Üniversitesi, FenEdebiyat Fakültesi, İstatistik Bölümü. http://ist.fef.omu.edu.tr/tr/hakkimizda/ders-notlari/GA-2017y.pdf 10.10..2020.

United Nations Educational Scientific and Cultural Organization (UNESCO) (2014). Global Citizenship Education: Preparing learners for the challenges of the 21st century. http://www.unesco.org/open-access/terms-use-ccbysa-en 15.05.2020.

United Nations Educational Scientific and Cultural Organization (UNESCO). (2015). Global citizienship education: Topics and learning objectives. https://unesdoc.unesco.org/ark:/48223/pf0000232993 15.05.2020.

Van Roekel, D. (2010). Global competence is a 21st century imperative. http://www.nea.org/assets/docs/HE/PB28A_Global_Competence11.pdf 03.06.2020.

Villereal, A. N. (2009). "Attaining Global Perspective: Preparing Undergraduate Students for an Interdependent World". Applied Research Projects, Texas State University-San Marcos.Paper 295. http:/lecommons.txstate.edu/arp/295 12.08.2020.

Wagner, T. (2008). The global achievement gap: Why even our best schools do not teach the new survival skills our children need, and what we can do about it. New York: Basic Books.

\section{Kaynakça Bilgisi / Citation Information}

Karaca Akarsu, C. ve Özdemir, M. (2021). Küresel Yetkinlik Ölçeğinin Türkçe uyarlama çalışması. OPUS-Uluslararası Toplum Araştırmaları Dergisi, 18(42), 5542-5576. DOI: 10.26466/opus.861584. 